\title{
Zn/F-doped tin oxide nanoparticles synthesized by laser pyrolysis: structural and optical properties
}

\author{
Florian Dumitrache ${ }^{1}$, Iuliana P. Morjan ${ }^{* 1}$, Elena Dutu ${ }^{1}$, Ion Morjan ${ }^{1}$, \\ Claudiu Teodor Fleaca ${ }^{1}$, Monica Scarisoreanu ${ }^{1}$, Alina llie ${ }^{1}$, Marius Dumitru ${ }^{1}$, \\ Cristian Mihailescu ${ }^{1}$, Adriana Smarandache ${ }^{1}$ and Gabriel Prodan ${ }^{2}$
}

\author{
Full Research Paper \\ Address: \\ ${ }^{1}$ National Institute for Laser, Plasma and Radiation Physics (NILPRP), \\ Atomistilor Str, no. 409, 077125, Bucharest-Magurele, Romania and \\ ${ }^{2}$ Ovidius University of Constanta, Mamaia Avenue no. 124, 900524 , \\ Constanta, Romania \\ Email: \\ Iuliana P. Morjan* - iulianamorjan@yahoo.com \\ * Corresponding author \\ Keywords: \\ laser pyrolysis; nanoparticles; optical bandgap; Zn/F-doped $\mathrm{SnO}_{2}$
}

Beilstein J. Nanotechnol. 2019, 10, 9-21.

doi:10.3762/bjnano.10.2

Received: 26 July 2018

Accepted: 16 November 2018

Published: 02 January 2019

Associate Editor: C. T. Yavuz

(c) 2019 Dumitrache et al.; licensee Beilstein-Institut. License and terms: see end of document.

\begin{abstract}
$\mathrm{Zn} / \mathrm{F}$ co-doped $\mathrm{SnO}_{2}$ nanoparticles with a mean diameter of less than $15 \mathrm{~nm}$ and a narrow size distribution were synthesized by a one-step laser pyrolysis technique using a reactive mixture containing tetramethyltin $\left(\mathrm{SnMe}_{4}\right)$ and diethylzinc $\left(\mathrm{ZnEt}_{2}\right)$ vapors, diluted $\mathrm{Ar}, \mathrm{O}_{2}$ and $\mathrm{SF}_{6}$. Their structural, morphological, optical and electrical properties are reported in this work. The X-ray diffraction (XRD) analysis shows that the nanoparticles possess a tetragonal $\mathrm{SnO}_{2}$ crystalline structure. The main diffraction patterns of stannous fluoride $\left(\mathrm{SnF}_{2}\right)$ were also identified and a reduction in intensity with increasing $\mathrm{Zn}$ percentage was evidenced. For the elemental composition estimation, energy dispersion X-ray spectroscopy (EDX) and X-ray photoelectron spectroscopy (XPS) measurements were performed. In general, both analyses showed that the $\mathrm{Zn}$ percentage increases with increasing $\mathrm{ZnEt}_{2}$ flow, accompanied at the same time by a decrease in the amount of $\mathrm{F}$ in the nanopowders when the same $\mathrm{SF}_{6}$ flow was employed. The Raman spectra of the nanoparticles show the influence of both $\mathrm{Zn}$ and $\mathrm{F}$ content and crystallite size. The fluorine presence is due to the catalytic partial decomposition of the $\mathrm{SF}_{6}$ laser energy transfer agent. In direct correlation with the increase in the $\mathrm{Zn}$ doping level, the bandgap of co-doped nanoparticles shifts to lower energy (from 3.55 to $2.88 \mathrm{eV}$ for the highest $\mathrm{Zn}$ dopant concentration).
\end{abstract}

\section{Introduction}

Recently, there has been growing interest in the field of transparent conducting oxides and wide bandgap oxide nanocrystalline materials such as tin oxide $\left(\mathrm{SnO}_{2}\right)$. It is generally agreed that $\mathrm{SnO}_{2}$ in its undoped form is an n-type semiconductor with a direct bandgap of $3.6 \mathrm{eV}$ at room temperature. Its n-type conductivity is due to oxygen vacancies in its rutile structure. 
The bandgap, starting from the bulk value, increases as the size of the nanocrystal decreases, due to electron confinement at the nanoscale - the so called "quantum size effect".

Therefore, it is very important to synthesize nanoparticles with a narrow size distribution and with a desired mean diameter in order to control their optical and electrical properties [1]. The properties that make nanometer-sized $\mathrm{SnO}_{2}$ highly valuable from a technological point of view are its electrical conductivity, which is strongly affected by the surface states and the presence of dopants, transparency in the visible light range, high reflectance in the infrared range, and its classification as not potentially toxic or harmful $[2,3]$. The introduction of defects in the crystal lattice acts to gradually decrease the bandgap of $\mathrm{SnO}_{2}$, which extends the emission spectra to the visible light range, making these nanoparticles technologically very important for optoelectronic devices and photovoltaic systems. Theoretically, the reported value of the reduced bandgap of tin oxide nanoparticles by introduction of defects to the crystal lattice is $\approx 0.7 \mathrm{eV}$ [4]. Generally, the doping of these semiconducting oxides with specific cations or anions is performed in order to increase their electrical conductivity while maintaining a high optical transparency in the visible range $[5,6]$. For the case of tin oxide, a comparative study using halogen anions $(\mathrm{F}, \mathrm{Cl}, \mathrm{Br}, \mathrm{I})$ as dopants shows that the fluorine anion induces the formation of thin films and exhibits the best performance in terms of transparency and conductivity [7] Today, the most used material for commercial applications that require both transparency and electrical conductivity (employed in liquid crystal displays, organic light emitting diodes (OLEDs), touchscreens or in solar panels) is indium tin oxide (ITO), which unfortunately suffers from high cost and a limited supply of indium [5]. One promising, lower cost, but good performing material alternatives to ITO for these types of applications is fluorine-doped tin oxide (FTO) [8]. Regarding the cation doping for the synthesis of tin-based transparent and conductive oxidic (TCO) materials, the literature has been focused on doping with i.) antimony by spray pyrolysis [9] or by sol-gel methods followed by spin-coating and annealing in different environments [10], ii.) manganese by long-time annealing of $\mathrm{Mn} / \mathrm{SnO}_{2}$ bilayers in air at $200{ }^{\circ} \mathrm{C}$ [11] or by co-precipitation [12], iii.) aluminum, copper or indium all by spray pyrolysis from ethanolic solutions [13] and iv.) iron by laser pyrolysis $[14,15]$ or by electron beam evaporation [16]. Cobalt-doped tin oxide has also been reported, and the resulting polycrystalline films were prepared by spin-coating and annealing from chloride ethanolic solutions resulted in lower bandgap values than pure $\mathrm{SnO}_{2}$ [17]. Highly conductive films based on amorphous Co-doped $\mathrm{SnO}_{2}$ were also synthesized using a pulsed spray evaporation chemical vapor deposition (CVD) technique [18]. One of the most reported cationic dopants for tin oxide is $\mathrm{Zn}^{2+}$, where the obtained zinc-doped tin oxide (ZTO) films show lower bandgap values (3.6-3.7 eV for $5-10$ wt \% $\mathrm{Zn})$ than the undoped ones $(3.97 \mathrm{eV})$. All of these were synthesized by sol-gel methods from $\mathrm{SnCl}_{2}$ and $\mathrm{ZnCl}_{2}$ hydropropanolic solutions and short-time annealed at $480{ }^{\circ} \mathrm{C}$ [19]. The same tendency was found in the sprayed (from $\mathrm{SnCl}_{2}$ and $\mathrm{Zn}\left(\mathrm{CH}_{3} \mathrm{COO}\right)_{2}$ in acidic $\mathrm{H}_{2} \mathrm{O}-\mathrm{CH}_{3} \mathrm{OH}$ solutions) and $400{ }^{\circ} \mathrm{C}$ heated films where the bandgap decreased from $3.85 \mathrm{eV}$ down to $3.57 \mathrm{eV}$ with increasing $\mathrm{Zn}$ weight concentration in the initial solution from 0 to $25 \%$ [20]. The facile substitution of $\mathrm{Zn}^{2+}$ into the $\mathrm{SnO}_{2}$ lattice containing $\mathrm{Sn}^{4+}$ cations can be explained by the similar values of their ionic radii $(0.74 \AA$ for $\mathrm{Zn}^{2+}$ and $0.71 \AA$ for $\left.\mathrm{Sn}^{4+}[21]\right)$ and thus each zinc ion replaces a tin ion accompanied by the appearance of an oxygen vacancy (equivalent with two holes) to maintain the crystal electrical neutrality. Moreover, it was hypothesized that part of the zinc ions can also occupy the interstitial sites in the $\mathrm{SnO}_{2}$ lattice, as reported for the $\mathrm{Zn}$-doped $\mathrm{SnO}_{2}$ nanoparticles obtained by the microwave solvothermal process, where a highly nonlinear relation was found between the zinc atomic doping percent and bandgap values [21]. Another strategy for improving the properties of tin oxide consists of the simultaneous doping with both cations and anions. In the case of a high aluminum and lower sulfur co-doped film made by spray pyrolysis at $480{ }^{\circ} \mathrm{C}$, the transparency increased and the grain size was significantly reduced for the optimal composition [22]. This approach benefits from the reduction of the number of recombination centers and enhancement of "the electron-hole pair separation to stimulate the change in the bandgap by eliminating the impurity states" by charge compensation between positive and negative ion dopants, and it can also "facilitate the overall mixing of the impurity states and VB/CB" (valence band/conduction band) "by adjusting the position of bandgap to obtain an optimized narrow value" [23]. Thus, using a solution-based single-source precursor (Er-doped $\mathrm{KSnF}_{3}$ ), oxygen-vacancy-rich nanocrystals of co-doped $\mathrm{Er}$ and $\mathrm{F} \mathrm{SnO}_{2}$ were obtained at low temperature with an estimated $4.18 \mathrm{eV}$ bandgap value [24]. Also, the 1 atom \% Nd-doped FTO film obtained by spray pyrolysis at $500{ }^{\circ} \mathrm{C}$ presented the lowest sheet resistance and resistivity values, which was accompanied by a $4.15 \mathrm{eV}$ bandgap - a value $4.21 \mathrm{eV}$ lower than that of FTO obtained under similar conditions. Also, in this case, the bandgap values decreased with increasing metal dopant content, down to $3.93 \mathrm{eV}$ for 4 atom \% $\mathrm{Nd}[24]$.

The FTO films were also successfully tested for other applications such as anticorrosive coatings on steel for fuel cell bipolar plates [25], sensors for liquefied petroleum gas [26], photocatalysts for rhodamine $6 \mathrm{G}$ dye degradation in aqueous solution [27] and were proposed as a thermal UV sensor for high-radiation environments [4]. Moreover, the ZTO materials were also 
employed as volatile organic compound (VOC) (such as methanol, ethanol or acetone vapors) sensors [28], as an anode for Li-ion microbatteries [29], as photocatalysts for brilliant green dye degradation in solution under solar light [30] and even as a component for supercapacitors [31].

The in situ synthesis of $\mathrm{SnO}_{2}$-based nanoparticles co-doped with $\mathrm{F}$ and $\mathrm{Zn}$ is demonstrated in this work. For this purpose we use the pyrolysis of $\mathrm{SnMe}_{4}$ and $\mathrm{ZnEt}_{2}$ sensitized with a $\mathrm{SF}_{6}$ gas flow, all in oxidative mixtures. We also report a study on the structural, optical and electrical properties of such $\mathrm{Zn} / \mathrm{F}$ co-doped $\mathrm{SnO}_{2}$ nanoparticles. Depending on the experimental parameters, different $\mathrm{Zn}$ and $\mathrm{F}$ doping levels in $\mathrm{SnO}_{2}$-based nanocrystals were obtained. To the best of our knowledge, $\mathrm{Zn} /$ F-doped tin oxide nanoparticles with low $\mathrm{Zn}$ and high $\mathrm{F}$ content have been prepared for the first time. Related fluorine-doped zinc tin oxide (FZTO) thin films with higher zinc concentration (from 5.5 to 35.5 atom \%) and lower fluorine content ( 0.62 to 3.49 atom \%) made by spray pyrolysis showing high transparency and bandgap values between 3.86 and $4.45 \mathrm{eV}$ have also been reported [32]. Other researchers have used radio frequency magnetron sputtering of mixed $30 \mathrm{wt} \% \mathrm{ZnO}$ and 70 wt $\% \mathrm{SnO}_{2}$ targets to obtain similar FZTO films, yet their reported different bandgap values were shown to increase with the vacuum annealing treatment temperature (from $3.41 \mathrm{eV}$ at $300{ }^{\circ} \mathrm{C}$ to $3.60 \mathrm{eV}$ at $600{ }^{\circ} \mathrm{C}$ ), where the amorphous to crystalline conversion was observed only at $600{ }^{\circ} \mathrm{C}$, accompanied by an almost complete fluorine loss [33].

\section{Results and Discussion}

\section{Structural properties}

The X-ray diffraction (XRD) patterns of Zn/F co-doped, F-doped and undoped $\mathrm{SnO}_{2}$ nanoparticles are superposed in Figure 1. The ratio, $R$, between the $\mathrm{SnMe}_{4}$ and $\mathrm{ZnEt}_{2}$ flows is shown on the right of the figure, near the sample name. In all cases, each XRD pattern clearly demonstrated the nanocrystalline feature of the analyzed powders. The most evident diffraction peaks (see the green arrows) correspond to the tetragonal rutile structure of the $\mathrm{SnO}_{2}$ phase (PDF No: 00-041$1445)$; thus the identified peaks centered at $26.8^{\circ}, 34^{\circ}, 38^{\circ}$, $51.9^{\circ}$, and $54.8^{\circ}$ can be assigned to (110), (101), (200), (211) and (220) crystal planes of this phase, respectively. Also the main diffraction patterns of stannous fluoride, $\mathrm{SnF}_{2}$ (PDF No: 00-015-0744 blue arrows), and stannous oxide, SnO (PDF No: 04-005-4541 red arrows), are distinguished in those samples with a low $\mathrm{Zn}$ doping level $\left(\mathrm{ZTO}_{0.05}, \mathrm{ZTO}_{0.15}\right.$ and $\left.\mathrm{ZTO}_{0.25}\right)$ as well as in the only F-doped $\left(\mathrm{ZTO}_{\mathrm{st}}\right)$ and undoped $\left(\mathrm{SnO}_{2}\right)$ powders. The most significant peaks of the $\mathrm{SnF}_{2}$ phase are identified for the $\mathrm{ZTO}_{\text {st }}$ powder, where their intensity tends to decrease with increasing $\mathrm{Zn}$ percentage. No phases corresponding to zinc or other zinc compounds are observed in any of the analyzed samples. For instance, regardless of the $\mathrm{Zn}$ doping degree, the presence of the main $\mathrm{ZnO}$ peak (101) at $2 \theta \approx 36.5^{\circ}$ was not distinguished. This result highlighted that at this $\mathrm{Zn}$ doping level there is no segregation process toward some $\mathrm{Zn}$-rich crystalline phases such as $\mathrm{Zn}_{2} \mathrm{SnO}_{4}$. It is worth to noting that the undoped reference sample is the only one where the clear signature of a stannous oxide phase can be observed, even when the amount of tin precursor and oxygen used for their synthesis is the same as that used for the $\mathrm{ZTO}_{\text {st }}$ sample, where $\mathrm{SF}_{6}$ was used as a sensitizer instead $\mathrm{C}_{2} \mathrm{H}_{4}$. Due to the better infrared absorption coefficient of $\mathrm{SF}_{6}$, we had to employ a larger amount of $\mathrm{C}_{2} \mathrm{H}_{4}$ to obtain the same laser-induced heating effect. Thus, the $\mathrm{C}_{2} \mathrm{H}_{4}$ competes with the $\mathrm{Sn}\left(\mathrm{CH}_{3}\right)_{4}$ vapors for the limited quantity of available oxidizing agent $\left(\mathrm{O}_{2}\right)$, resulting in a mixture of $\mathrm{SnO}_{2}$ and $\mathrm{SnO}$ phases in the case of the undoped sample. We previously reported a similar oxygen deficient environment using tetramethyl tin laser

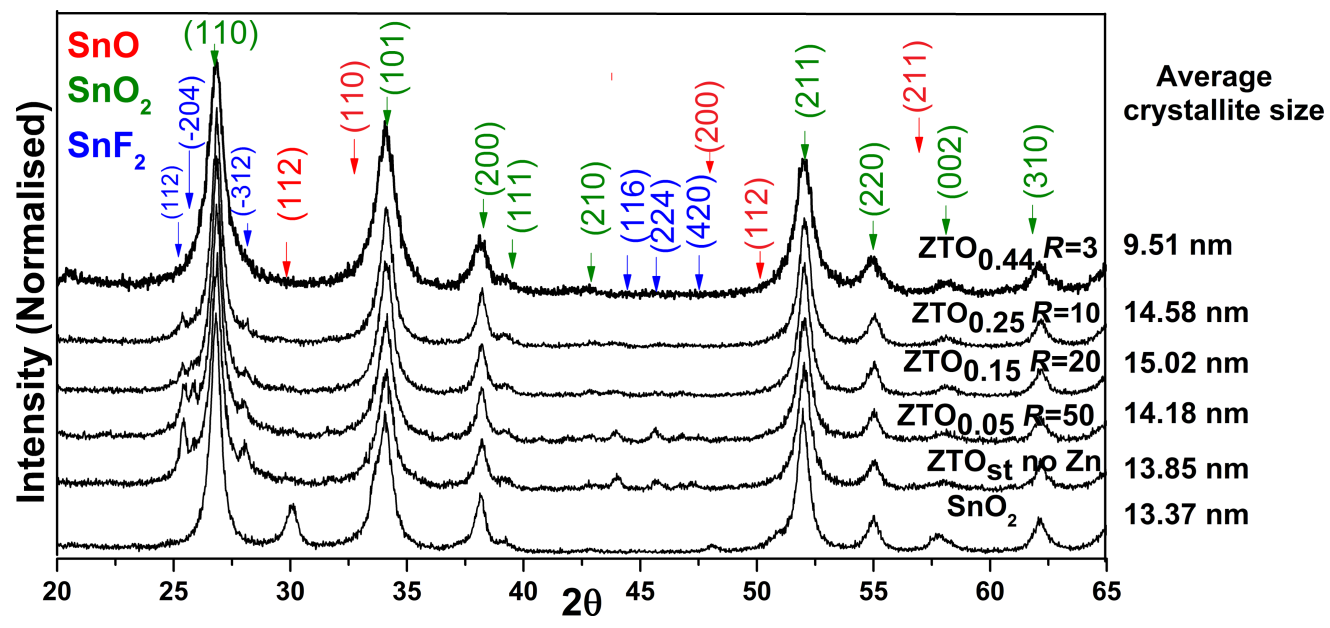

Figure 1: $\mathrm{XRD}$ spectra of the $\mathrm{Zn} / \mathrm{F}$ co-doped, $\mathrm{F}$-doped and undoped $\mathrm{SnO}_{2}$ nanoparticles. 
pyrolytic oxidation, where metallic tin was also found in addition to $\mathrm{SnO}_{2}$ and $\mathrm{SnO}$ phases [14].

The presence of fluorine is explained by the catalytic decomposition of the sensitizer that acts also as a fluorine donor. A probable explanation of the $\mathrm{SnF}_{2} \mathrm{XRD}$ pattern intensity decrease with increasing $\mathrm{Zn}$ doping is the presence of $\mathrm{ZnEt}_{2}$ that acts as an inhibitor of $\mathrm{SF}_{6}$ decomposition, in particular, by lowering the temperature in the synthesis zone (it decreases gradually from $615^{\circ} \mathrm{C}$ at the $\mathrm{ZTO}_{\text {st }}$ sample to $560{ }^{\circ} \mathrm{C}$ for the $\mathrm{ZTO}_{0.44}$ sample). These observations lead to the conclusion that the dominant crystalline structure is $\mathrm{SnO}_{2}$, with the secondary phase of $\mathrm{SnF}_{2}$ in the case of small $\mathrm{Zn}$ doping levels, and the $\mathrm{Zn}$ atoms probably substitute $S n$ sites in the oxide phase, thus changing the optical and electrical properties of the $\mathrm{ZTO}_{\mathrm{st}}$ standard sample. Yet, the simultaneous substitutional fluorine doping of $\mathrm{SnO}_{2}$ must also be considered, as will be discussed in the paragraph when XRD and XPS analyses are presented. Considering the most intense peak (101) of the dominant phase $\mathrm{SnO}_{2}$, the crystallite size $(D)$ was calculated using Scherrer's equation:

$$
D=(K \lambda) /(\beta \cos \theta),
$$

where the dimensionless shape factor $K$ is 0.9 , the X-ray wavelength $\lambda$ is $1.5418 \AA$, while $\beta$ is the peak full-width at halfmaximum (FWHM) and $\theta$ is the Bragg angle. The FWHM was evaluated for the first three peak profiles ((110), (101) and (200)) using a pseudo-Voigt function. In all cases, except the $\mathrm{ZTO}_{0.44}$ sample, the crystalline size remains constant around $14 \mathrm{~nm}$, but for the highest $\mathrm{Zn}$ doping level, a significant crystalline size decrease was observed. This tendency is correlated with the flame temperature decrease generated by decreasing $R=D_{\mathrm{SnMe} 4} / D_{\mathrm{ZnEt} 2}$, while keeping the sensitizer flow constant.

In order to estimate the elemental composition for the $\mathrm{Zn} / \mathrm{F}$ doped $\mathrm{SnO}_{2}$ powders, EDX and XPS measurements were conducted; the results are presented in Table 1. In the XPS measurements, the peaks centered around $487 \mathrm{eV}, 494 \mathrm{eV}$,
$531.43 \mathrm{eV}, 684 \mathrm{eV}, 1022 \mathrm{eV}$ and $1045 \mathrm{eV}$ were assigned to $\mathrm{Sn} 3 \mathrm{~d}_{5 / 2}, \mathrm{Sn} 3 \mathrm{~d}_{3 / 2}, \mathrm{O} 1 \mathrm{~s}, \mathrm{~F} 1 \mathrm{~s}, \mathrm{Zn} 2 \mathrm{p}_{3 / 2}$ and $\mathrm{Zn} 2 \mathrm{p}_{1 / 2}$, respectively, based on earlier reports [23,34]. In general, both analyses are in agreement with the composition of the reactive gas mixture. Thus, the zinc percentage in powder increases with increasing $\mathrm{ZnEt}_{2}$ flow. The presence of carbon in the powder is minor and is derived from the decomposition of methyl and ethyl radicals released by volatile organometallic compounds. This fact can be explained by an insufficient (less than stoichiometricly required) quantity of oxidant for the total oxidation of alkylmetallic precursors to oxides $\left(\mathrm{SnO}_{2}\right.$ and $\mathrm{ZnO}$, in fact $\mathrm{Zn}$-doped $\mathrm{SnO}_{2}$ ), $\mathrm{CO}_{2}$ and $\mathrm{H}_{2} \mathrm{O}$ in the laser pyrolysis reaction zone. Due to the much higher reactivity of metals, the metal oxides are formed with priority, and the unoxidized alkyl radicals from the precursors will undergo a complex process involving reactions such as dimerization, dehydrogenation, polymerization, reticulation, aromatization and carbonization with the final formation of amorphous hydrogenated carbon. For the $\mathrm{ZTO}_{0.44}$ case, in spite of an apparent oxygen excess, the carbon is still formed (the EDX-extracted carbon atomic percent is the smallest from all ZTO powders) and this fact can be attributed to an insufficient diffusion between the oxygen from the annular flow and alkylmetals vapors from the central flow. Also, for the undoped sample, the ethylene sensitizer seems to be another major carbon source in the resulting metal-oxide-based powder, similar to the process of ethylene-sensitized $\mathrm{TiCl}_{4}$ oxidative laser pyrolysis that we previously reported $[35,36]$.

Also, the elemental estimations revealed the significant presence of $\mathrm{F}$ in all as-synthesized powders in accordance with the $\mathrm{SnF}_{2}$ phase identified in XRD patterns. As discussed before, the fluorine presence in nanoparticles may be explained by the catalytic partial decomposition of $\mathrm{SF}_{6}$. Typically, this gas is stable in the temperature range chosen for these experiments: $500-650{ }^{\circ} \mathrm{C}$. An increased concentration of $\mathrm{F}$ is observed for XPS analysis; this is explained by a compositional gradient in the nanopowder (the superficial $F$ concentration is higher than in the inner zone of the nanoparticle).

\begin{tabular}{|c|c|c|c|c|c|c|c|c|c|c|}
\hline \multirow[t]{3}{*}{ Sample } & \multicolumn{10}{|c|}{ Elemental composition (atom \%) } \\
\hline & \multicolumn{2}{|c|}{ C } & \multicolumn{2}{|c|}{0} & \multicolumn{2}{|c|}{ Sn } & \multicolumn{2}{|c|}{$\mathrm{F}$} & \multicolumn{2}{|c|}{$\mathrm{Zn}$} \\
\hline & EDX & XPS & EDX & XPS & EDX & XPS & EDX & XPS & EDX & XPS \\
\hline $\mathrm{ZTO}_{\text {st }}$ & 9.29 & 6.97 & 45.37 & 38 & 32.47 & 21.6 & 12.87 & 27 & 0 & 0 \\
\hline $\mathrm{ZTO}_{0.05}$ & 9.18 & 7.3 & 49.16 & 42 & 31.91 & 26 & 9.75 & 21.6 & $\operatorname{Tr}^{a}$ & 0 \\
\hline $\mathrm{ZTO}_{0.15}$ & 8.67 & 6.57 & 56.15 & 50.53 & 30.68 & 25.29 & 4.38 & 16.69 & 0.12 & 0.25 \\
\hline $\mathrm{ZTO}_{0.25}$ & 9.09 & 9.40 & 54.26 & 48.16 & 30.92 & 22.24 & 5.45 & 15.30 & 0.29 & 0.25 \\
\hline $\mathrm{ZTO}_{0.44}$ & 8.18 & 14.96 & 54.22 & 53.08 & 27.22 & 15.02 & 6.64 & 12.39 & 3.74 & 4.55 \\
\hline
\end{tabular}

aTr. means less than 0.1 atom $\% \mathrm{Zn}$. 
The XPS analysis is only sensitive to surface areas, with a penetration depth of a few nanometers, while EDX evaluates the average composition on the irradiated area (containing more than 1000 particles in average), thus its penetration depth exceeds the mean particle size (few tens of nanometers). Consequently, the predominant presence of $\mathrm{F}$ at the nanopowder surface may be evidence for the assumption that freshly formed nanoclusters have a catalytic role in the partial decomposition of $\mathrm{SF}_{6}$.

The elemental analysis reveals that the laser pyrolysis method can be used to synthesize nanoparticles with a large variation of $\mathrm{Zn}$ doping (from 4 to 0.1 atom \%), by controlling only the $\mathrm{SnMe}_{4}$ to $\mathrm{ZnEt}_{2}$ ratio in the reagent mixture. Also, there is no clear evidence of sulfur in any of the synthesized powders either from EDX analysis (no peaks around $2.13 \mathrm{KeV}-\mathrm{S} \mathrm{K} \alpha$ emission line) or XPS spectra (no peaks or shoulder around $164 \mathrm{eV}$ ascribed to $\mathrm{S} 2 \mathrm{p}_{3 / 2}$ binding energy). This fact may be explained by the following decomposition reaction: $\mathrm{SF}_{6} \rightarrow \mathrm{SF}_{4}+\mathrm{F}_{2}$ [37] that seems to be catalyzed in our case by the freshly formed tinbased clusters. Using the same $\mathrm{SF}_{6}$ flow rate $(0.5 \mathrm{sccm})$, the highest $\mathrm{F}$ content was found in the $\mathrm{ZTO}_{\mathrm{st}}$ sample where none of the central Ar streams pass through $\mathrm{ZnEt}_{2}$. The most probable explanation comes from the reactive flame temperature when the presence of $\mathrm{ZnEt}_{2}$ vapors slightly cools the flame due to its endothermal decomposition. This consequently creates a hotter reaction zone - and as in the case of the $\mathrm{ZTO}_{\mathrm{st}}$ sample synthesis without the zinc precursor, this favors the $\mathrm{SF}_{6}$ decomposition with fluorine release. The presence of an increased $\mathrm{Zn}$ content is observed in the $\mathrm{ZTO}_{0.44}$ sample and is directly dependent on the $\mathrm{Zn} / \mathrm{Sn}$ vapor flow ratio.

High-resolution XPS core level spectra of Sn3d, O1s, F1s and $\mathrm{Zn} 2 \mathrm{p}$ were made for the highest $\mathrm{Zn}$-doped sample $\left(\mathrm{ZTO}_{0.44}\right)$ and the only the fluorine-doped sample $\left(\mathrm{ZTO}_{\mathrm{st}}\right)$. The binding energies were calibrated using the $\mathrm{C} 1 \mathrm{~s}$ peak at $284.4 \mathrm{eV}$ in order to compensate the surface charging effects. From Figure 2 it can observed that in the case of $\mathrm{ZTO}_{\text {st }}$ sample, Sn exhibits only one oxidation state, while the $\mathrm{Zn}$ doping is accompanied by the formation of a secondary $\mathrm{SnO}$ phase, see Figure 2a. Also, the binding energy of $\mathrm{Sn}$ in the $\mathrm{Zn}$-doped $\mathrm{SnO}_{2}$ nanoparticles slightly decreases with the $\mathrm{Zn}$ doping degree from 486.8 to $485.15 \mathrm{eV}$. This behavior was previously observed in the hydrothermally synthesized Zn-doped powder and it can be attributed to: (i) changing effects, or, (ii) to the oxygen deficiency since the Sn binding energy changes with Sn oxidation nature [34]. Furthermore, a significant contribution may come from the presence of $\mathrm{Sn}-\mathrm{F}$ bonds because they have a higher $\mathrm{Sn}_{3} \mathrm{~d}_{5 / 2}$ binding energy: $487.2 \mathrm{eV}$ for $\mathrm{SnF}_{2}$ [38].

Figure $2 \mathrm{~b}$ and $2 \mathrm{f}$ present a comparison of the $\mathrm{O} 1 \mathrm{~s}$ transition peak. For the $\mathrm{ZTO}_{\mathrm{st}}$ sample, the observed O1s binding energy has a major peak centered at $530.65 \mathrm{eV}$, which corresponds exactly to the value for $\mathrm{SnO}_{2}$. The second peak centered at $531.8 \mathrm{eV}$ can be attributed to the $\mathrm{O}-\mathrm{C}$ bond [39] or to $\mathrm{O}^{2-}$ in the oxygen deficient regions [40]. In the case of sample $\mathrm{ZTO}_{0.44}$ the main O1s peak shifts to a lower value: $530.45 \mathrm{eV}$; we observed that this trend is correlated with the $\mathrm{Zn}$ doping degree. The third peak could be assigned to $\mathrm{Sn}-\mathrm{O}-\mathrm{Zn}$ coordination [41]. As shown in Figure 2d, the binding energy of the $\mathrm{Zn} 2 \mathrm{p}_{3 / 2}$ and $\mathrm{Zn} 2 \mathrm{p}_{1 / 2}$ transition peaks is 1021.7 and $1044.9 \mathrm{eV}$, respectively, which confirm the presence of $\mathrm{Zn}$ in the doped $\mathrm{SnO}_{2}$ nanoparticles, and possible traces of $\mathrm{Zn}$ in the only fluorine-doped sample, probably due to powder collector contamination from previous experiments. The F1s spectrum (Figure 2c) consists of three peaks originating from: $\mathrm{ZnF}_{2}$ at $684.1 \mathrm{eV}, \mathrm{SnF}_{2}$ at 684.9 and partially fluorinated carbons (contamination from the interaction of fluorine provided by SF6 decomposition with the alkyl radicals from metallic precursors) at $686.35 \mathrm{eV}$. The $\approx 685 \mathrm{eV} \mathrm{F1s} \mathrm{XPS} \mathrm{peak} \mathrm{was} \mathrm{also} \mathrm{detected} \mathrm{in}$ fluoride-doped $\mathrm{SnO}_{2}$ from milled PVdF (polyvynilidene fluoride) $/ \mathrm{SnO}_{2}$ mixtures [42] and in solid or hollow fluoride-mediated hydrothermal synthesized $\mathrm{SnO}_{2}$ nanostructured microspheres [43]. Moreover, for the half hour milled sample from [42], the stannous fluoride XRD peaks can also be identified at $2 \theta \approx 25^{\circ}$ and $2 \theta \approx 27^{\circ}$. In brief, the XPS results indicate that $\mathrm{Zn}$ atoms are incorporated into the $\mathrm{SnO}_{2}$ crystal lattice through the substitution of Sn sites.

In Figure 3a, a high-resolution TEM (HRTEM) image of a Zn/ F-doped $\mathrm{SnO}_{2}$ sample (labeled $\mathrm{ZTO}_{0.44}$ ) and its mean size distribution (inset in Figure 3a) are presented. The polyhedral crystalline tin dioxide aggregated nanoparticles can be clearly seen in the HRTEM image. Also, a very thin disordered layer can be identified on the crystallite surface, most likely being composed of the amorphous (hydrogenated) carbon derived from alkylmetal precursors as discussed before.

The values of the mean diameters for all the doped samples are shown in Table 2. It can be seen that in the $\mathrm{ZTO}_{\text {st }}$ and $\mathrm{ZTO}_{0.05}$ nanopowders, by increasing the degree of $F$ doping, and in the (quasi)absence of $\mathrm{Zn}$, the crystallite size and the average particle diameter decreases. One also can notice that the smallest mean crystallite size $(9.51 \mathrm{~nm})$ can be found for $\mathrm{ZTO}_{0.44}$ powder, where the $\mathrm{F}$ doping level is the lowest (yet not zero) while those of $\mathrm{Zn}$ is the highest. Also, when the $\mathrm{F}$ and $\mathrm{Zn}$ doping concentration is reduced (from $\mathrm{ZTO}_{0.44}$ to $\mathrm{ZTO}_{0.25}$ and to $\mathrm{ZTO}_{0.15}$ ), an inverse tendency of increasing crystallite size was observed (from 9.51, 14.58 and $15.02 \mathrm{~nm}$, respectively), yet without a clear correlation with the average diameter of the nanoparticles measured from TEM images. The tendency of the reduction in the mean crystallite size with increasing $\mathrm{Zn}$ concentration (without $\mathrm{ZnO}$ phase segregation) was also observed 
Beilstein J. Nanotechnol. 2019, 10, 9-21.

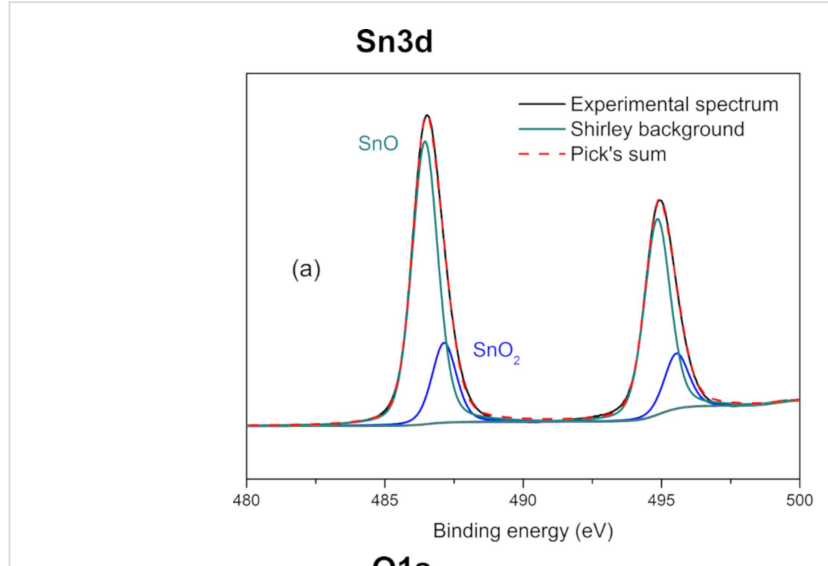

$\operatorname{Sn} 3 d$
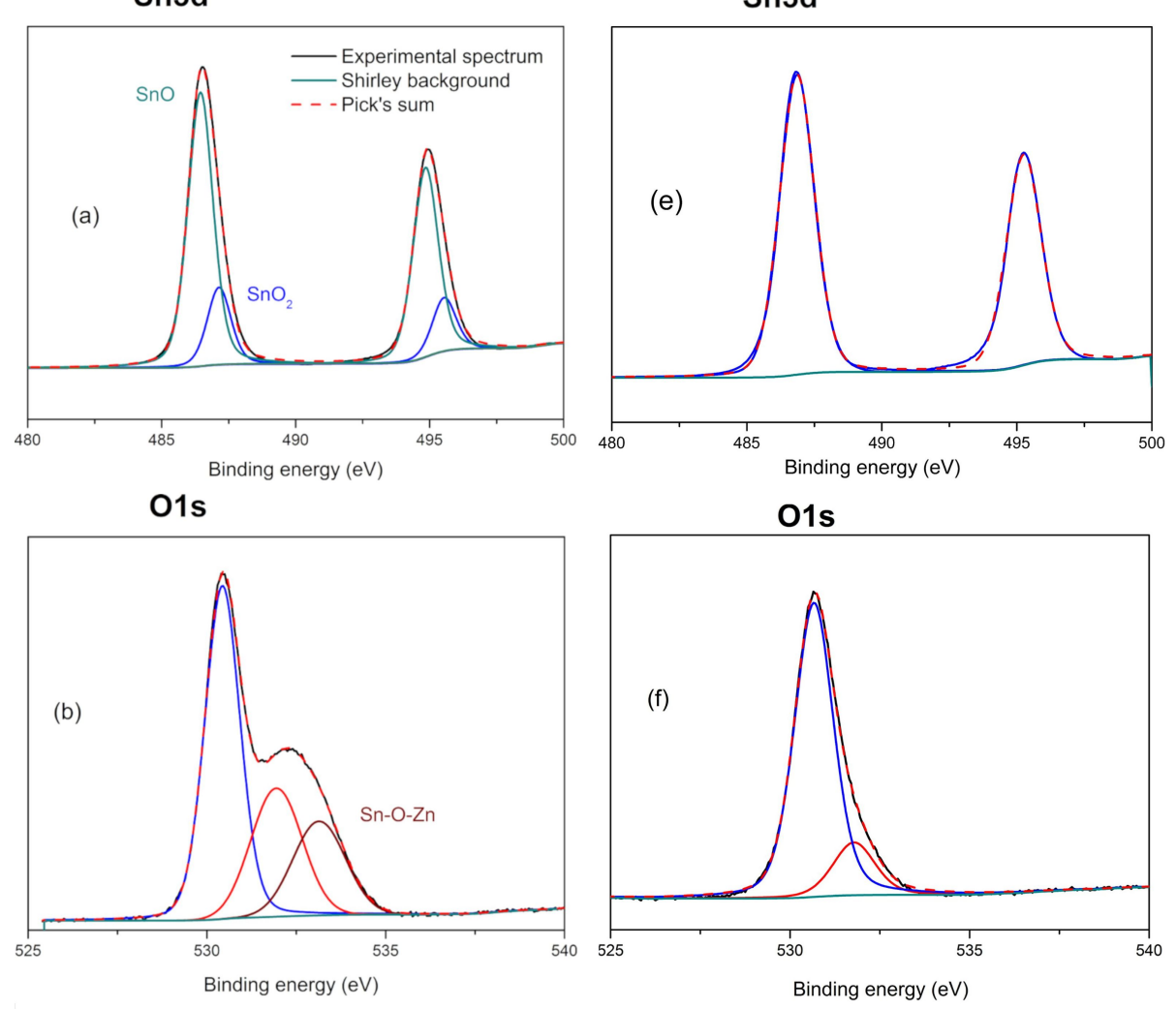

01s

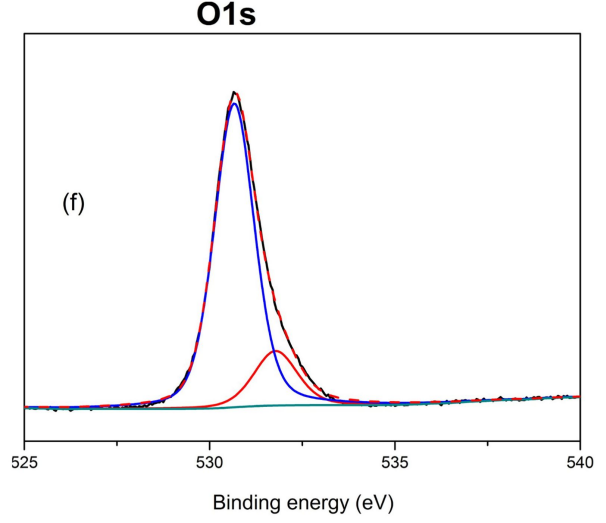

F1s
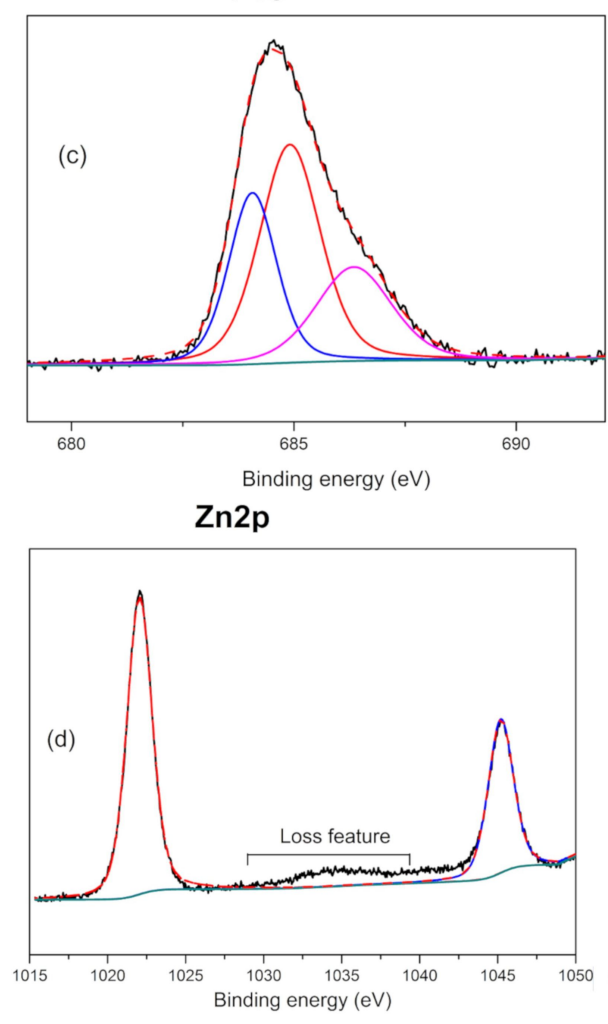

F1s
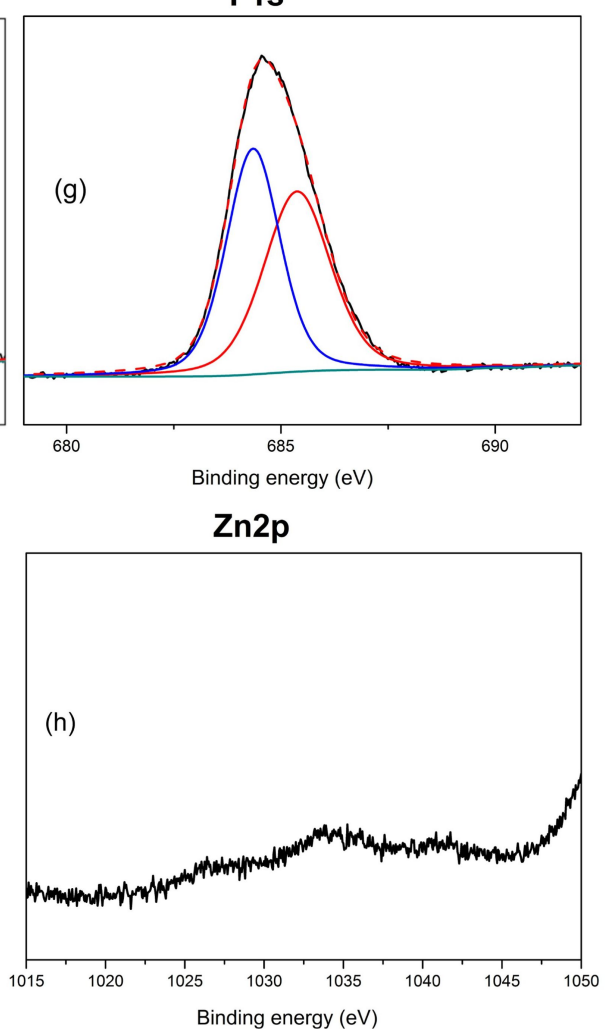

Figure 2: XPS high-resolution spectra of: (a, b, c, d) $\mathrm{Zn} / \mathrm{F}$-doped $\mathrm{SnO}_{2}$ nanoparticles (sample $\mathrm{ZTO}_{0.44}$ ) and (e, f, g, h) F-doped $\mathrm{SnO} \mathrm{O}_{2}$ nanoparticles (sample $\mathrm{ZTO}_{\text {st }}$ ).

14 

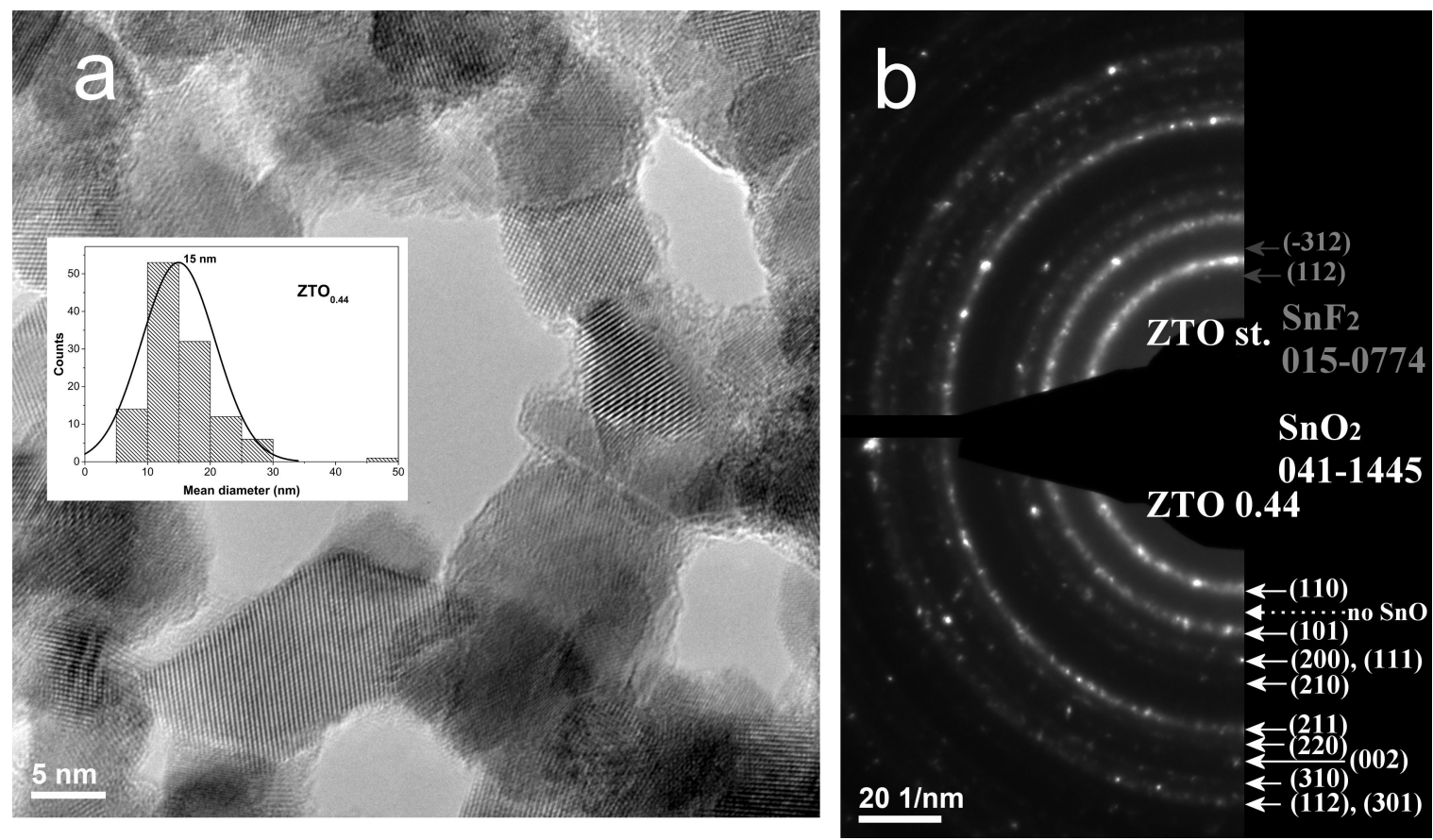

Figure 3: a) HRTEM image of sample $\mathrm{ZTO}_{0.44}$ and its mean size distribution; b) SAED patterns of $\mathrm{ZTO}_{\mathrm{st}}$ (top) and $\mathrm{ZTO}_{0.44}$ (bottom) samples.

Table 2: Dependence of the mean diameter and crystallite size with $\mathrm{F}$ and $\mathrm{Zn}$ (atom \%) doping level.

\begin{tabular}{llllll} 
Sample & Mean diameter (nm) & Mean XRD crystallite size $(\mathrm{nm})$ & \multicolumn{2}{c}{ EDX } \\
& & & $\mathrm{F}($ atom \%) & $\mathrm{Zn}($ atom \%) & Total F + Zn (atom \%) \\
\hline $\mathrm{ZTO}_{0.05}$ & 18 & 14.18 & 9.75 & 0 & 9.75 \\
$\mathrm{ZTO}_{\mathrm{st}}$ & 14 & 13.85 & 12.87 & 0 & 12.87 \\
$\mathrm{ZTO}_{0.44}$ & 15 & 9.51 & 6.64 & 3.74 & 10.38 \\
$\mathrm{ZTO}_{0.25}$ & 18.5 & 14.58 & 5.45 & 0.29 & 5.74 \\
$\mathrm{ZTO}_{0.15}$ & 15 & 15.02 & 4.38 & 0.12 & 4.5
\end{tabular}

for the case of $\mathrm{Zn}$-doped $\mathrm{SnO}_{2}$ nanocrystals prepared by a solidstate reaction from stannous chloride and zinc acetate, yet in this case, a mixture of tetragonal rutile-type and minority orthorhombic tin dioxide phases was identified [44].

The crystalline phases identified from SAED (see Figure 3b) images are consistent with those from XRD, indicating structural uniformity up to the level of nanoparticle agglomeration containing several dozen crystalline domains. From the superposed SAED images of the $\mathrm{ZTO}_{\text {st }}$ sample (Zn-free, only fluorine doped) (top) and the $\mathrm{ZTO}_{0.44}$ sample (bottom), it can be observed that almost all diffraction rings belong to the $\mathrm{SnO}_{2}$ phase (PDF No: 00-041-1445). No rings ascribable to the maximum diffraction planes of $\mathrm{SnO}(110)$ and $\mathrm{SnF}_{2}(112)$ as secondary phases can be identified in the SAED image of $\mathrm{Zn}$-doped sample $\left(\mathrm{ZTO}_{0.44}\right)$. For the $\mathrm{ZTO}_{\text {st }}$ sample, the pres- ence of a few $\mathrm{SnF}_{2}$ crystals is probable. In the SAED image of this fluorine only doped tin oxide powder, we have identified diffraction dots positioned towards the center in agreement with the most intense crystalline plane planes (112) and (-312) of the $\mathrm{SnF}_{2}$ phase. Also, in both SAED images there are no diffraction rings or dots placed in $\mathrm{ZnO}(101): 2.48 \AA$ and $\mathrm{Zn}(101)$ : $2.09 \AA$ positions.

\section{Raman spectroscopy}

Raman spectroscopy, commonly employed to provide qualitative information via phononic behavior regarding the crystalline nature of materials, is a useful tool for investigating disorder in oxide materials. Figure 4a presents a typical room temperature Raman spectra of as-synthesized F or Zn/F-doped $\mathrm{SnO}_{2}$ nanopowders. The Raman spectra analyzed in this work does not include the $1300-1500 \mathrm{~cm}^{-1}$ window. The carbon 

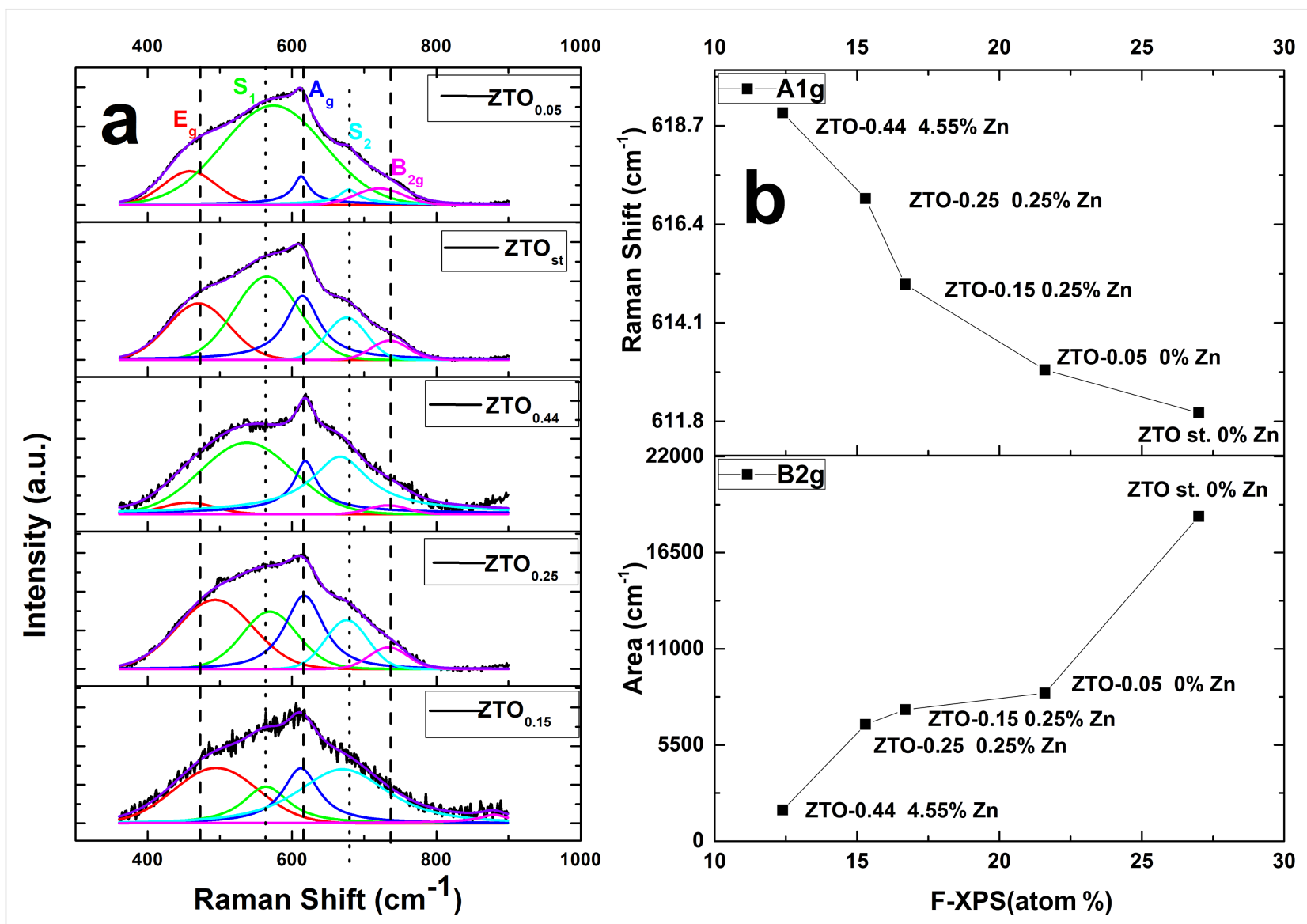

Figure 4: a) The Raman spectra of the as-prepared samples; b) The dependence from the Raman and XPS analysis.

Raman component has not been approached in this analysis due to low amorphous $\mathrm{C}$ content in the samples, which, combined with their photoluminescent feature, makes the Raman $\mathrm{C}$ vibrational modes too weak to be clearly distinguished in the measured spectra against the background noise.

Three fundamental Raman peaks are observed at around 470, 618 and $730 \mathrm{~cm}^{-1}$, corresponding to $\mathrm{E}_{\mathrm{g}}, \mathrm{A}_{1 \mathrm{~g}}, \mathrm{~B}_{2 \mathrm{~g}}$ first-order Raman active modes of rutile-type phase of $\mathrm{SnO}_{2}$ [45-47]. The $\mathrm{B}_{2 \mathrm{~g}}$ and $\mathrm{A}_{1 \mathrm{~g}}$ modes are both related to the contraction and expansion of $\mathrm{Sn}-\mathrm{O}$ bonds in the perpendicular plane to the $c$-axis. The $\mathrm{E}_{\mathrm{g}}$ mode is related to the oxygen vibration in the direction of the $c$-axis $[48,49]$. According to Diéguez et al. [49], the band S1 located at around $570 \mathrm{~cm}^{-1}$ is linked to amorphous $\mathrm{SnO}_{2}$. The correlation between the intensity of the Raman band with the size of $\mathrm{SnO}_{2}$ nanoparticles is also revealed.

For samples presented in this article, the double doping with $\mathrm{F} / \mathrm{Zn}$ of $\mathrm{SnO}_{2}$ nanoparticles leads to different dependencies. In Figure 4a the Raman spectra and the corresponding bands after their deconvolution with a Pearson 7 function are presented. After the deconvolution, a correlation can be made between the fluorine doping atomic percent (from the XPS analysis) and the Raman shift value of the $A_{1 g}$ band or the $B_{2 g}$ peak area as shown in Figure $4 \mathrm{~b}$. Thus, with the increase of fluorine content in the powders, the $A_{1 g}$ position shifts toward lower wave numbers, whereas the $B_{2 g}$ band area increases about 100 times.

The $\mathrm{F}$ and $\mathrm{Zn}$ content, in infrared-laser-assisted synthesized $\mathrm{SnO}_{2}$ nanoparticles, shifts the $\mathrm{A}_{1 \mathrm{~g}}$ Raman mode also due to a cumulative effect of an increase in the crystallite size combined with $\mathrm{Zn}$ doping of rutile crystalline structure. One can observe (Figure 4b) a direct dependence of the mode frequency with XPS Zn content detected on the nanoparticle surface. This shifting correlated with the $\mathrm{B}_{2 \mathrm{~g}}$ Raman mode area increase indicates nanoparticle surface disorder induced by $\mathrm{F}$ attachment.

$\mathrm{S} 1$ and S2 bands appear as a disorder activation consequence [25] inferred by F, Zn and nanocrystallite size. When the F concentration is high (without $\mathrm{Zn}$ doping) the disorder is considered to be surface induced, while for a sample with a high $\mathrm{Zn}$ concentration ( $\mathrm{EDX}-3.74$ atom \%), $\mathrm{ZTO}_{0.44}$, the disorder is volume generated, along with a depreciation in the crystalline 
quality with respect to $\mathrm{SnO}_{2}$ size. This behavior is sustained by the $\mathrm{E}_{\mathrm{g}}$ mode extinction in the last sample.

\section{Optical and electrical properties}

Figure 5a shows UV-vis absorbance spectra of only F-doped and $\mathrm{Zn} / \mathrm{F}$ co-doped $\mathrm{SnO}_{2}$ nanoparticles. It is well known that the absorbance depends on factors such as the bandgap, grain size, oxygen deficiency, surface roughness, and impurity centers [21].

The direct bandgaps of the nanoparticles were determined from the Tauc relation [50-52] given by:

$$
\alpha h v=A\left(h v-E_{\mathrm{g}}\right)^{n}
$$

where $\alpha$ is the absorption coefficient, $A$ is a constant, $h v$ is the photon energy, $n$ is an index that can take different values depending on the type of transition. In this case $n$ equals to $1 / 2$, corresponding to a direct transition. The optical energy gap $E_{\mathrm{g}}$ can be estimated by plotting $(\alpha h v)^{2}$ versus $(h v)$, then by extrapolating the linear portion of the absorption edge to the photon energy axis at the value $(\alpha h v)^{2}=0$.

As shown in Figure 5b and reported in Table 3, the bandgap energy of the $\mathrm{SnO}_{2}$ materials show a decrease with decreasing $\mathrm{F}$ doping concentration and with the increase of $\mathrm{Zn}$ doping concentration. The bandgap of our standard undoped sample was found to be $3.55 \mathrm{eV}$, which is lower than that of bulk $\mathrm{SnO}_{2}$ $(3.6 \mathrm{eV})$. This may be attributed to the impurity clustering which occurs in heavily doped semiconductors. Also, the carbon presence in all (including the reference without $\mathrm{F}$ and $\mathrm{Zn}$ ) of our laser-synthesized tin-oxide-based nanopowders can also
Table 3: Dependence of the bandgap and resistivity $(\rho)$ with $F$ and $\mathrm{Zn}$ (atom \%) doping level.

\begin{tabular}{lllll} 
Sample & Bandgap $(\mathrm{eV})$ & $\mathrm{F}$ atom \% & $\mathrm{Zn}$ atom \% & $\mathrm{P}(\Omega \cdot \mathrm{cm})$ \\
\hline $\mathrm{ZTO}_{\text {st }}$ & 3.55 & 27 & 0 & 156.18 \\
$\mathrm{ZTO}_{0.05}$ & 3.47 & 21.6 & 0 & 149.33 \\
$\mathrm{ZTO}_{0.15}$ & 3.3 & 16.69 & 0.25 & 65.76 \\
$\mathrm{ZTO}_{0.25}$ & 3.18 & 15.30 & 0.25 & 57.54 \\
$\mathrm{ZTO}_{0.44}$ & 2.83 & 12.39 & 4.55 & 1246.7
\end{tabular}

influence the optical properties, including the bandgap values. A clear optical behavior influence of the presence of carbon layers on tin dioxide can be observed for the $\mathrm{SnO}_{2} @ \mathrm{C}$ and $\mathrm{SnO}_{2} @ \mathrm{SiO}_{2} @ \mathrm{C}$ nanostructured microspheres ( $\mathrm{C}$ symbolizing here reduced graphene oxide, rGO) reported in [53], where the UV-vis spectra show a clear increase in absorbance (mostly in the visible domain, but also in the 320-400 nm UV zone) when compared with pure $\mathrm{SnO}_{2}$. Consequently, the resulting bandgap values diminished from $3.6 \mathrm{eV}$ in pure $\mathrm{SnO}_{2}$ down to $3.2 \mathrm{eV}$ for both $\mathrm{SnO}_{2} @ \mathrm{SiO}_{2} @ \mathrm{C}$ and $\mathrm{SnO}_{2} @ \mathrm{C}$ samples [53]. A similar behavior can also be supposed for our carbon-containing tin oxide samples, yet in our case, the UV-vis absorption in this region seems to be considerably lower. Unfortunately, in the methods employed to extract the absorbance (diffuse reflectance spectroscopy using $\mathrm{BaSO}_{4}$ reflectance standard in [53] vs direct absorption from ethanolic suspensions in our study), the different carbonaceous structure of the coating and the use of arbitrary units make a direct comparison difficult. Regarding the zinc ion doping bandgap influence for the $\mathrm{Zn} / \mathrm{F}$ co-doped $\mathrm{SnO}_{2}$ systems, a previous report showed a similar tendency with ours of decreasing bandgap (from 4.40 to 4.13 and to $3.86 \mathrm{eV}$ ) with increasing $\mathrm{Zn}$ content (from 0.5 to 1.5 to 2.3 surface atom $\% \mathrm{Zn}$ doping) for low $\mathrm{F}$ doping levels $(0.37,0.53$ and 0.29 atom $\% \mathrm{~F}$,
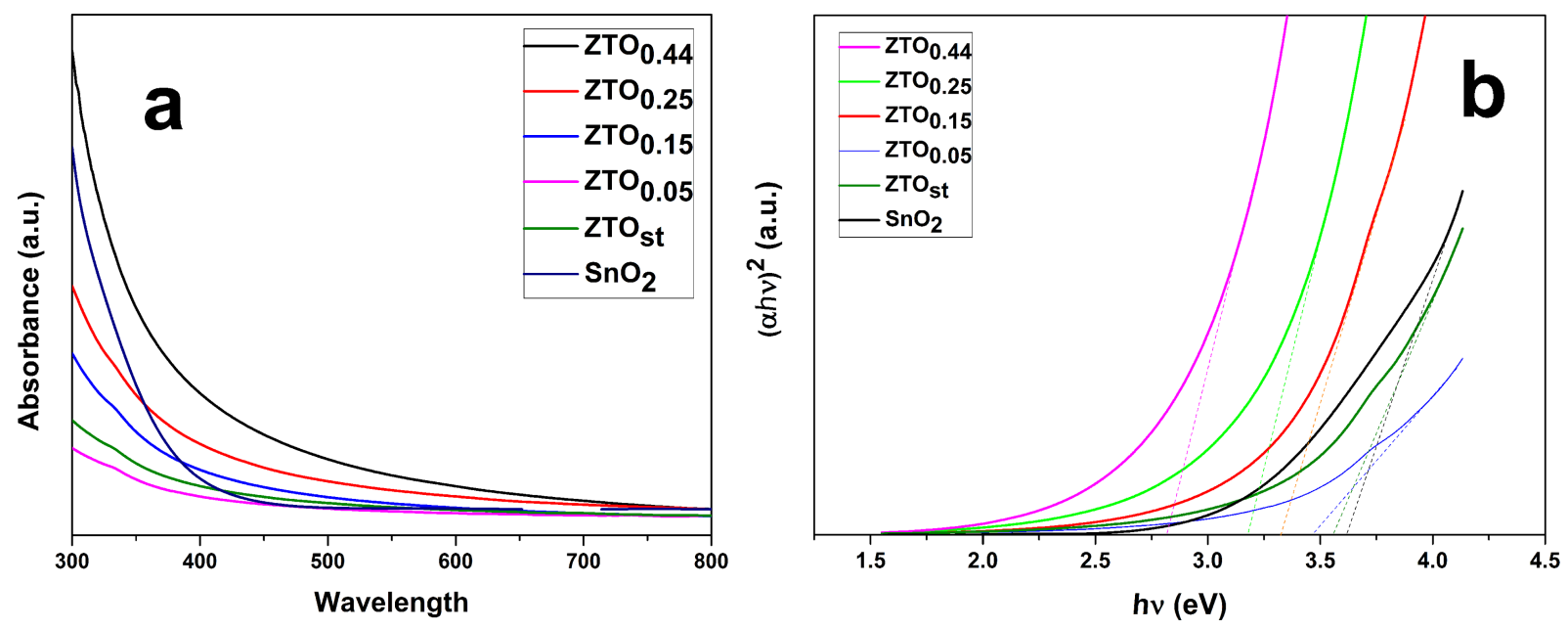

Figure 5: a) Optical absorption spectra of the nanoparticles, b) Tauc's plot for $\mathrm{Zn} / \mathrm{F}$-doped and undoped $\mathrm{SnO}_{2}$ nanoparticles ( $\alpha$ hv) ${ }^{2}$ versus $(h v$ ). 
respectively) and heavy carbon surface contaminated tin dioxide films [32]. The authors discussed two possible reasons for this decreasing trend that also can be considered for our powders: the lower bandgap value for $\mathrm{ZnO}(3.2 \mathrm{eV})$ vs that of $\mathrm{SnO}_{2}(3.8 \mathrm{eV})$ and the "formation of Urbach tails at high impurity concentration" [32]. Moreover, as highlighted in the introduction, some sprayed $\mathrm{Zn}$-doped $\mathrm{SnO}_{2}$ films also show the same tendency [20]. The energy bandgap measurements can help in engineering so that $\mathrm{Zn} / \mathrm{F}$-doped $\mathrm{SnO}_{2}$ can be considered as a typical transparent conducting oxide (TCO) suitable for solar cell applications.

Thin films were prepared from the as-synthesized powders using spin-coating and found to have an apparent density of around $0.8 \mathrm{~g} / \mathrm{cm}^{3}$. The resistivity at room temperature is on the order of tens to hundreds of $\Omega \cdot \mathrm{cm}$. These electrical values are in agreement with those reported in literature considering that the resulting films have a low particle packing density $\left(\mathrm{SnO}_{2}\right.$ bulk density is $7.0 \mathrm{~g} / \mathrm{cm}^{3}$ ). $\mathrm{Zn}$-doped $\mathrm{SnO}_{2}$ films have resistivity values slightly lower than the only F-doped ones (Figure 6 and Table 3, last column), and have an optimum $\mathrm{Zn}$ doping level for sample $\mathrm{ZTO}_{0.25}\left(\mathrm{ZnEt}_{2}\right.$ flow/SnMe 4 flow $\left.=0.1\right)$.

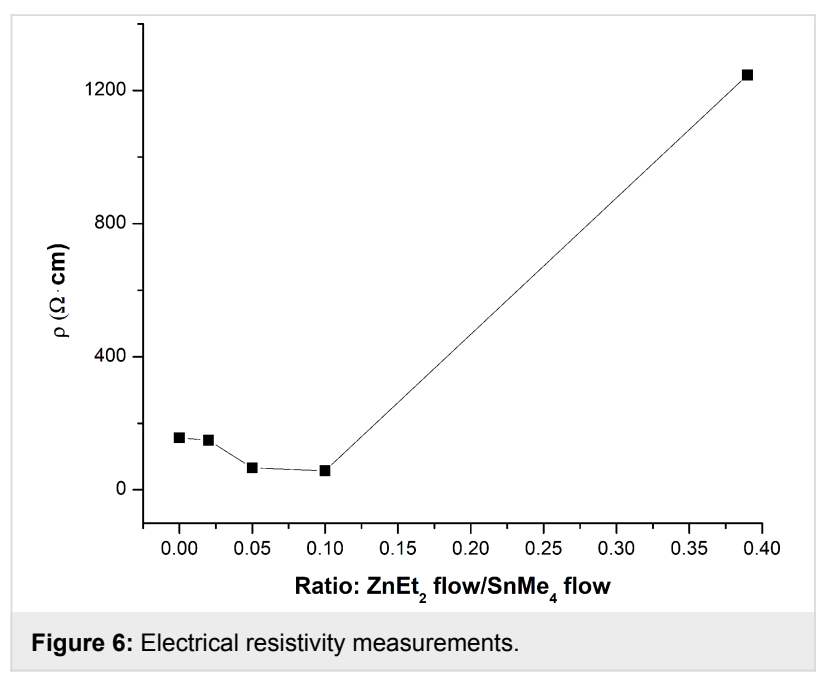

\section{Conclusion}

The laser pyrolysis technique has been successfully employed to obtain $\mathrm{Zn}$ and $\mathrm{F}$ co-doped $\mathrm{SnO}_{2}$ nanopowders, according to XPS and EDX analyses. The dominant crystalline structure, as indicated by $\mathrm{XRD}$, is $\mathrm{SnO}_{2}$ with the secondary phase of $\mathrm{SnF}_{2}$ in the case of small $\mathrm{Zn}$ and high $\mathrm{F}$ doping levels. The mean crystallite size is $\approx 14-15 \mathrm{~nm}$, but at the highest $\mathrm{Zn}$ doping level, a significant crystalline size decrease down to $\approx 9 \mathrm{~nm}$ was observed. The crystalline phases identified from SAED images are consistent with those resulting from $\mathrm{XRD}$, indicating that almost all diffraction rings belong to the $\mathrm{SnO}_{2}$ phase. Three fundamental Raman peaks are observed at around 470,618 and
$730 \mathrm{~cm}^{-1}$, corresponding to first-order Raman active modes, $\mathrm{E}_{\mathrm{g}}$, $\mathrm{A}_{1 \mathrm{~g}}, \mathrm{~B}_{2 \mathrm{~g}}$ of rutile phase of $\mathrm{SnO}_{2}$. It has been demonstrated that by the increasing the fluorine concentration, the $\mathrm{A}_{1 \mathrm{~g}}$ position shift toward lower wavenumbers and the $\mathrm{B}_{2 \mathrm{~g}}$ band area grows about 100 times. The optimum resistivity of the co-doped $\mathrm{SnO}_{2}$ films is $57.54 \Omega \cdot \mathrm{cm}$ for a $\mathrm{ZnEt}_{2}$ to $\mathrm{SnMe}_{4}$ flow ratio of 0.1 . In order to understand the effect of zinc and fluorine addition on the optical and electrical properties for TCO applications, further experiments are planned and results will be reported in the future.

\section{Experimental}

Laser pyrolysis is a versatile method to synthesize nanoparticles. The process is based on the resonance between the emission line of a continuous wave $\mathrm{CO}_{2}$ laser $(\lambda=10.6 \mu \mathrm{m})$ and the infrared absorption band of at least one gas-phase component. An additional substance, the so-called sensitizer, is used in the case of non-absorbing gas/vapor precursors. The experimental arrangement consists of a heat-resistant glass reactor with a cross-sectional configuration in which the precursor gas stream, introduced vertically from the bottom and having a laminar flow, perpendicularly intersects the laser beam. Laser irradiation of the gaseous precursor is achieved by means of a focusing lens located in front of the reaction chamber. This technique is mainly employed for its advantages: (a) the welldefined interaction volume where no interactions with the reactor chamber walls occur, and hence, no contamination; (b) the production of very fine particles (usually less than $50 \mathrm{~nm}$ ); (c) the small distribution of nanoparticle size; (d) control of growth rate and residence time in reaction zone; and (e) continuous working regime scalable to pilot station and even to industrial production.

As raw or auxiliary materials we employed volatile diethylzinc ( $\mathrm{ZnEt}_{2}, \geq 52 \mathrm{wt} \% \mathrm{Zn}$ content) and tetramethyltin ( $\mathrm{SnMe}_{4}, 95 \%$ purity) liquids from Sigma and sulfur hexafluoride $\left(\mathrm{SF}_{6}\right)$, oxygen $\left(\mathrm{O}_{2}\right)$, argon (Ar) (99.99999 vol \%) and ethylene $\left(\mathrm{C}_{2} \mathrm{H}_{4}\right)$ $(99.999$ vol \%) bottled gases from Linde.

The reactive precursors used to obtain zinc-doped tin nanopowders, $\mathrm{SnMe}_{4}$ and $\mathrm{ZnEt}_{2}$, have no infrared absorption bands around the $\mathrm{CO}_{2}$ laser wavelength, which makes the introduction of a laser energy absorber (sensitizer) such as $\mathrm{SF}_{6}$ necessary. The $\mathrm{SF}_{6}$ molecules absorb part of the infrared laser beam energy and distribute it through collisions to the other gas species in the irradiation area. Thus, the reactive mixture very quickly reaches the temperature where the precursors start to decompose, forming Zn/F-doped Sn-based (and sometimes even $\mathrm{SnF}_{2}$ ) clusters. At the same time, due to the presence of an oxidative environment, the freshly formed clusters oxidize to $\mathrm{SnO}$ or $\mathrm{SnO}_{2}$ nanodomains. Also, a reference sample doped 
only with fluorine (noted $\mathrm{FTO}_{\mathrm{st}}$ ) was synthesized in the absence of the zinc precursor, whereas the other reference sample (noted $\left.\mathrm{SnO}_{2}\right)$ was obtained also in the absence of $\mathrm{Zn}\left(\mathrm{C}_{2} \mathrm{H}_{5}\right)_{2}$ vapors, yet using $\mathrm{C}_{2} \mathrm{H}_{4}$ as a sensitizer instead of $\mathrm{SF}_{6}$ (see Table 4) to avoid both $\mathrm{Zn}$ and $\mathrm{F}$ doping.

In this study an inlet gas system of three concentric tubes was used. Different Ar flows served as carriers for the $\mathrm{SnMe}_{4}$ and $\mathrm{ZnEt}_{2}$ vapors. The main reactive stream consisting of $\mathrm{SnMe}_{4} /$ $\mathrm{ZnEt}_{2}$ vapors and $\mathrm{SF}_{6}$ emerges into the reactor through the central nozzle tube. This central stream is directed towards the irradiated zone where the laser beam was focused to $1.5 \mathrm{~mm}$ diameter. An $\mathrm{O}_{2} / \mathrm{Ar}$ gas mixture passes through the middle annular gas admission, surrounding the central reactive stream in the irradiated area and creating a more-or-less oxidative environment. Simultaneously, the laminar flows of these two reactive streams are adjusted by an inert gas stream (Ar) that flows through the external (also annular) gas admission.

The total flow values for all three streams were adjusted in order to generate the same gas velocity above the admission nozzle $(\approx 75 \mathrm{~cm} / \mathrm{s})$. In accordance with this restriction, the total central flow is maintained at $13.25 \mathrm{sccm}$, the median flow at $65 \mathrm{sccm}$ and the external flow at $1000 \mathrm{sccm}$. Complementarily, two Ar flows are used to flush the $\mathrm{ZnSe}$ windows in order to impede the solid particle deposition on them. The reaction products that emerge from the reaction zone under the form of very fine, solid suspended particles were then entrained by the gas flow. The powder is trapped in the filter-containing collector and the gases, passing through the filter, leave the system with the aid of a vacuum pump.

The experiments take place at a constant laser power at $110 \mathrm{~W}$ and pressure of 450 mbar. Table 4 lists the main experimental parameters for which the change of the reactive and the dilution gas flows maintain a constant total inlet flow through the three zones at the entrance to the reaction chamber. In order to control the $\mathrm{Zn}$ doping level we have the possibility to divide the Ar flow designated to carry the $\mathrm{ZnEt}_{2}$ vapors; part of this flow can pass through the $\mathrm{Zn}$-precursor-containing bubbler.

The powders resulting from the laser pyrolysis experiments were first characterized by XRD structural analysis (determination of crystalline phases and their mean dimension). Thus, $\mathrm{X}$-ray measurements of Sn-based powders were performed at room temperature using the X-ray diffraction equipment X-Pert PRO MPD from PANalytical. The data is transmitted and then processed by the PANalytical X'Pert High-Score Plus software package. The XRD analytical method use the setup for polycrystalline powders in which the sample is exposed in front of a monochromatic X-ray beam having a variable incidence $\theta$ angle and a constant wavelength corresponding to the $\mathrm{K} \alpha$ copper line $(\lambda=1.5418 \AA)$. Transmission electron microscopy (TEM and HRTEM) using a Tecnai F30 G2 (300 kV) instrument, was used to investigate the particle morphology, as well as the crystalline domains by selected area electron diffraction (SAED) analysis. Energy dispersion X-ray spectroscopy (EDX) was performed using a scanning electron microscopy (SEM-Inspect TM S50) with an acceleration voltage of $15 \mathrm{kV}$, using a SiLi detector cooled with liquid nitrogen. This method can give information on the elemental analysis (excluding hydrogen) on the samples.

The analysis of absorbance $(A)$ data obtained by UV-vis-NIR spectrophotometry was performed on $0.01 \mathrm{~g}$ nanopowder sample suspended in $20 \mathrm{~mL}$ ethanol. The absorption spectra were registered using the computer-aided double-beam UV-vis-NIR spectrophotometer (Lambda 950, Perkin Elmer, USA) between $300-800 \mathrm{~nm}$. The experimental spectral resolution was $0.05 \mathrm{~nm}$ for the UV-vis spectral domain. A measurement uncertainty of $\pm 0.004 \%$ specified by the manufacturer for the device was considered.

The XPS measurements were performed in an ESCALAB Xi+ (Thermo SCIENTIFIC Surface Analysis) setup equipped with a

Table 4: Experimental parameters for the different production conditions discussed in this article.

\begin{tabular}{|c|c|c|c|c|c|c|c|c|c|c|c|c|}
\hline \multirow[t]{2}{*}{ Sample } & \multirow[b]{2}{*}{$\begin{array}{l}\mathrm{D}_{\mathrm{SF} 6} \\
\text { [sccm] }\end{array}$} & \multirow[b]{2}{*}{$\begin{array}{l}\mathrm{D}_{\mathrm{Ar} / \mathrm{ZnEt} 2} \\
{[\mathrm{sccm}]}\end{array}$} & \multirow[b]{2}{*}{$\begin{array}{l}\mathrm{D}_{\mathrm{ZnEt} 2} \\
{[\mathrm{sccm}]}\end{array}$} & \multirow[b]{2}{*}{$\begin{array}{l}\text { DAr by } \\
\text { pass } Z n \\
\text { [sccm] }\end{array}$} & \multicolumn{3}{|c|}{ Central nozzle } & \multirow[b]{2}{*}{$\begin{array}{l}\mathrm{D}_{\mathrm{SnMe} 4} \\
\text { [sccm] }\end{array}$} & \multirow[b]{2}{*}{$\begin{array}{l}R= \\
D_{\text {SnMe4/ }} \\
D_{\text {ZnEt2 }}\end{array}$} & \multicolumn{2}{|c|}{ Middle nozzle } & \multirow{2}{*}{$\begin{array}{l}\text { External } \\
\text { nozzle } \\
\text { DAr_ext } \\
\text { [sccm] }\end{array}$} \\
\hline & & & & & $\begin{array}{l}\mathrm{D}_{\mathrm{C} 2 \mathrm{H} 4} \\
{[\mathrm{sccm}]}\end{array}$ & $\begin{array}{l}\mathrm{D}_{\mathrm{Ar} / \mathrm{SnMe}} 4 \\
{[\mathrm{sccm}]}\end{array}$ & $\begin{array}{l}\mathrm{D}_{\mathrm{C} 2 \mathrm{H} 4 / \mathrm{SnMe} 4} \\
{[\mathrm{sccm}]}\end{array}$ & & & $\begin{array}{l}\mathrm{D}_{\mathrm{O} 2} \\
{[\mathrm{sccm}]}\end{array}$ & $\begin{array}{l}\text { D Ar_int } \\
\text { [sccm] }\end{array}$ & \\
\hline $\mathrm{SnO}_{2}$ & - & - & - & - & 5.25 & - & 5 & 2.50 & - & 15 & 50 & 1000 \\
\hline $\mathrm{ZTO}_{\mathrm{st}}$ & 0.50 & - & - & 5.25 & - & 5 & - & 2.50 & - & 15 & 50 & 1000 \\
\hline $\mathrm{ZTO}_{0.05}$ & 0.50 & 1 & 0.05 & 4.20 & - & 5 & - & 2.50 & 50 & 15 & 50 & 1000 \\
\hline $\mathrm{ZTO}_{0.15}$ & 0.50 & 3.15 & 0.15 & - & - & 6.30 & - & 3.15 & 20 & 15 & 50 & 1000 \\
\hline $\mathrm{ZTO}_{0.25}$ & 0.50 & 5 & 0.25 & - & - & 5 & - & 2.50 & 10 & 15 & 50 & 1000 \\
\hline $\mathrm{ZTO}_{0.44}$ & 0.50 & 8.95 & 0.44 & - & - & 2.24 & - & 1.12 & 3 & 15 & 50 & 1000 \\
\hline
\end{tabular}


multichannel hemispherical electron analyzer (dual X-ray source) operating with $\mathrm{Al} \mathrm{K} \alpha$ radiation $(h v=1486.2 \mathrm{eV})$, using $\mathrm{C} 1 \mathrm{~s}(284.4 \mathrm{eV})$ as the energy reference. XPS data were recorded by slightly pressing the powders on Si wafers. Then the samples were outgassed in the device prechamber at room temperature up to a pressure of $<2 \times 10^{-8}$ Torr in order to remove chemisorbed molecules from their surfaces. The surface chemical compositions and the oxidation states were estimated from the XPS spectra by calculating the integral of each peak after subtraction of the "S-shaped" Shirley-type background using the appropriate experimental sensitivity factors by means of "Avantage" software (version 5.978).

The acquisition of Raman spectra was achieved with a JASCO NRS-7200 Raman spectrometer using a blue laser source emitting at $532 \mathrm{~nm}$.

In order to evaluate the powder resistivity, pellets with $10 \mathrm{~mm}$ metallized base diameter and $0.5 \mathrm{~mm}$ thickness were prepared by pressing $900 \mathrm{mg}$ from each nanopowder up to $150 \mathrm{~atm}$ at room temperature. The resulting pellets have around $72 \%$ from $\mathrm{SnO}_{2}$ theoretical density.

\section{Acknowledgements}

This work has been financed by the National Authority for Research and Innovation from Romania in the frame of Nucleus programme- LAPLAS V contract 3N/2018 and the Romanian project PN-III-P1-1.2 PCCDI 46/2018.

\section{ORCID ${ }^{\circledR}$ iDs}

Alina llie - https://orcid.org/0000-0002-9806-0567

Adriana Smarandache - https://orcid.org/0000-0002-4586-7551

Gabriel Prodan - https://orcid.org/0000-0002-9323-7562

\section{References}

1. Maffeïs, T. G. G.; Owen, G. T.; Malagù, C.; Martinelli, G.; Kennedy, M. K.; Kruis, F. E.; Wilks, S. P. Surf. Sci. 2004, 550, 21-25 doi:10.1016/j.susc.2003.11.041

2. Canada Gazette Part II, Vol. 128, No. 9, May 04 1994, SOR/94-311. https://pollution-waste.canada.ca/substances-search/Substance/Displa ySubstanceDetails?ld=1332-29-2 (accessed Oct 23, 2018).

3. Zulfiqar; Yuan, Y.; Jiang, Q.; Yang, J.; Feng, L.; Wang, W.; Ye, Z.; Lu, J. J. Mater. Sci.: Mater. Electron. 2016, 27, 9541-9549. doi:10.1007/s10854-016-5006-3

4. Kamble, V. B.; Umarji, A. M. AIP Adv. 2013, 3, 082120-082125. doi:10.1063/1.4819451

5. Fortunato, E.; Ginley, D.; Hosono, H.; Paine, D. C. MRS Bull. 2007, 32, 242-247. doi:10.1557/mrs2007.29

6. Nagarajan, R.; Kumar, V.; Ahmad, S. Indian J. Chem. 2012, 51A, 145-154.

7. Noor, N.; Parkin, I. P. Thin Solid Films 2013, 532, 26-30. doi:10.1016/j.tsf.2012.10.110
8. Banyamin, Z. Y.; Kelly, P. J.; West, G.; Boardman, J. Coatings 2014, 4, 732-746. doi:10.3390/coatings4040732

9. Babar, A. R.; Shinde, S. S.; Moholkar, A. V.; Bhosale, C. H.; Kim, J. H.; Rajpure, K. Y. J. Semicond. 2011, 32, 053001. doi:10.1088/1674-4926/32/5/053001

10. Woo, D.-C.; Koo, C.-Y.; Ma, H.-C.; Lee, H.-Y. Trans. Electr. Electron. Mater. 2012, 13, 241-244. doi:10.4313/teem.2012.13.5.241

11. Brahma, R.; Ghanashyam Krishna, M.; Bhatnagar, A. K. Bull. Mater. Sci. 2006, 29, 317-322. doi:10.1007/bf02706503

12. Saravanakumar, M.; Agilan, S.; Muthukumarasamy, N.; Rukkumani, V.; Marusamy, A.; Ranjitha, A. Acta Phys. Pol., A 2015, 127, 1656-1661. doi:10.12693/aphyspola.127.1656

13. Gurakar, S.; Serin, T.; Serin, N. Adv. Mater. Lett. 2014, 5, 309-314. doi:10.5185/amlett.2014.amwc.1016

14. Alexandrescu, R.; Morjan, I.; Dumitrache, F.; Birjega, R.; Fleaca, C.; Luculescu, C. R.; Popovici, E.; Soare, I.; Sandu, I.; Dutu, E.; Prodan, G. J. Optoelectron. Adv. Mater. 2010, 12, 599-604.

15. Wei, X.; Georgescu, R.; Ali, N.; Morjan, I.; George, T. A.; Dumitrache, F.; Birjega, R.; Chipara, M.; Skomski, R.; Sellmyer, D. J. J. Nanosci. Nanotechnol. 2012, 12, 9299-9301. doi:10.1166/jnn.2012.6784

16. Ghanaatshoar, M.; Moradi, M.; Khodabandeh, Z. J. Supercond. Novel Magn. 2013, 26, 995-999. doi:10.1007/s10948-012-1942-1

17. El Sayed, A. M.; Taha, S.; Shaban, M.; Said, G. Superlattices Microstruct. 2016, 95, 1-13. doi:10.1016/j.spmi.2016.04.017

18. Jiang, Y.; Li, Y.; Yan, M.; Bahlawane, N. J. Mater. Chem. 2012, 22, 16060-16065. doi:10.1039/c2jm32801a

19. Bhat, J. S.; Maddani, K. I.; Karguppikar, A. M. Bull. Mater. Sci. 2006, 29, 331-337. doi:10.1007/bf02706505

20. Vijayalakshmi, S.; Venkataraj, S.; Subramanian, M.; Jayavel, R. J. Phys. D: Appl. Phys. 2008, 41, 035505. doi:10.1088/0022-3727/41/3/035505

21. Selvi, E. T.; Sundar, S. M. Appl. Phys. A: Mater. Sci. Process. 2017, 123, 383. doi:10.1007/s00339-017-0995-1

22. Muramba, V.; Mageto, M.; Gaitho, F.; Odari, V.; Musembi, R.; Mureramanzi, S.; Ayodo, K. Am. J. Mater. Sci. 2015, 5, 23-30.

23. Kumar, V.; Uma, S.; Nagarajan, R. Turk. J. Phys. 2014, 38, 450-462. doi:10.3906/fiz-1405-4

24. Turgut, G.; Keskenler, E. F.; Aydın, S.; Yılmaz, M.; Doğan, S.; Düzgün, B. Phys. Scr. 2013, 87, 035602. doi:10.1088/0031-8949/87/03/035602

25. Park, J. H.; Jeon, B. J.; Lee, J. K. Surf. Coat. Technol. 2015, 277, 1-6. doi:10.1016/j.surfcoat.2015.06.067

26. Chaisitsak, S. Sensors 2011, 11, 7127-7140. doi:10.3390/s110707127

27. Kumar, V.; Govind, A.; Nagarajan, R. Inorg. Chem. 2011, 50, 5637-5645. doi:10.1021/ic2003436

28. Singh, D.; Kundu, V. S.; Maan, A. S. J. Mol. Struct. 2016, 1115, 250-257. doi:10.1016/j.molstruc.2016.02.091

29. Torabi, M.; Sadrnezhaad, S. K. J. Power Sources 2011, 196, 399-404. doi:10.1016/j.jpowsour.2010.06.028

30. Shanmugam, N.; Sathya, T.; Viruthagiri, G.; Kalyanasundaram, C.; Gobi, R.; Ragupathy, S. Appl. Surf. Sci. 2016, 360, 283-290. doi:10.1016/j.apsusc.2015.11.008

31. Saravanakumar, B.; Ravi, G.; Ganesh, V.; Ameen, F.; Al-Sabri, A.; Yuvakkumar, R. J. Sol-Gel Sci. Technol. 2018, 86, 521-535. doi:10.1007/s10971-018-4685-z 
32. Salameh, B.; Alsmadi, A. M.; El Akkad, F. Thin Solid Films 2017, 626, 76-84. doi:10.1016/j.tsf.2017.02.021

33. Pandey, R.; Cho, S. H.; Hwang, D. K.; Choi, W. K. Curr. Appl. Phys. 2014, 14, 850-855. doi:10.1016/j.cap.2014.03.020

34. Dou, X.; Sabba, D.; Mathews, N.; Wong, L. H.; Lam, Y. M.; Mhaisalkar, S. Chem. Mater. 2011, 23, 3938-3945. doi:10.1021/cm201366z

35. Alexandrescu, R.; Dumitrache, F.; Morjan, I.; Sandu, I.; Savoiu, M.; Voicu, I.; Fleaca, C.; Piticescu, R. Nanotechnology 2004, 15, 537-545. doi:10.1088/0957-4484/15/5/023

36. Fleaca, C. T.; Scarisoreanu, M.; Morjan, I.; Luculescu, C.; Niculescu, A.-M.; Badoi, A.; Vasile, E.; Kovacs, G. Appl. Surf. Sci. 2015, 336, 226-233. doi:10.1016/j.apsusc.2014.11.106

37. Tsai, W.-T. J. Fluorine Chem. 2007, 128, 1345-1352. doi:10.1016/j.jluchem.2007.06.008

38. NIST X-ray Photoelectron Spectroscopy Database, version 4.1. https://webbook.nist.gov (accessed July 20, 2018).

39. Akkad, F. E.; Joseph, S. J. Appl. Phys. 2012, 112, 023501. doi:10.1063/1.4736798

40. Fitzgerald, C. B.; Venkatesan, M.; Dorneles, L. S.; Gunning, R.; Stamenov, P.; Coey, J. M. D.; Stampe, P. A.; Kennedy, R. J.; Moreira, E. C.; Sias, U. S. Phys. Rev. B 2006, 74, 115307. doi:10.1103/physrevb.74.115307

41. Ramasamy, E.; Lee, J. Energy Environ. Sci. 2011, 4, 2529-2536. doi:10.1039/c1ee01123e

42. Senna, M.; Turianicová, E.; Šepelák, V.; Bruns, M.; Scholz, G.; Lebedkin, S.; Kübel, C.; Wang, D.; Kaňuchová, M.; Kaus, M.; Hahn, H. Solid State Sci. 2014, 30, 36-43. doi:10.1016/j.solidstatesciences.2014.02.010

43. Wang, H.; Fu, F.; Zhang, F.; Wang, H.-E.; Kershaw, S. V.; Xu, J.; Sun, S.-G.; Rogach, A. L. J. Mater. Chem. 2012, 22, 2140-2148. doi:10.1039/c1jm14839g

44. Tian, S.; Gao, Y.; Zeng, D.; Xie, C. J. Am. Ceram. Soc. 2012, 95, 436-442. doi:10.1111/j.1551-2916.2011.04957.x

45. Haddad, N.; Ben Ayadi, Z.; Mahdhi, H.; Djessas, K. J. Mater. Sci.: Mater. Electron. 2017, 28, 15457-15465. doi:10.1007/s10854-017-7433-1

46. Zhao, Q.; Ju, D.; Deng, X.; Huang, J.; Cao, B.; Xu, X. Sci. Rep. 2015, 5, 7874. doi:10.1038/srep07874

47. Jia, T.; Chen, J.; Deng, Z.; Fu, F.; Zhao, J.; Wang, X.; Long, F. Mater. Sci. Eng., B 2014, 189, 32-37. doi:10.1016/j.mseb.2014.07.006

48. Peercy, P. S.; Morosin, B. Phys. Rev. B 1973, 7, 2779-2786. doi:10.1103/physrevb.7.2779

49. Diéguez, A.; Romano-Rodríguez, A.; Vilà, A.; Morante, J. R. J. Appl. Phys. 2001, 90, 1550-1557. doi:10.1063/1.1385573

50. Tauc, J.; Grigorovici, R.; Vancu, A. Phys. Status Solidi 1966, 15, 627-637. doi:10.1002/pssb.19660150224

51. Viezbicke, B. D.; Patel, S.; Davis, B. E.; Birnie, D. P., III. Phys. Status Solidi B 2015, 252, 1700-1710. doi:10.1002/pssb.201552007

52. Srikant, V.; Clarke, D. R. J. Appl. Phys. 1998, 83, 5447-5451. doi:10.1063/1.367375

53. Shen, H.; Zhao, X.; Duan, L.; Liu, R.; Wu, H.; Hou, T.; Jiang, X.; Gao, H. Appl. Surf. Sci. 2017, 391, 627-634. doi:10.1016/j.apsusc.2016.06.031

\section{License and Terms}

This is an Open Access article under the terms of the Creative Commons Attribution License (http://creativecommons.org/licenses/by/4.0). Please note that the reuse, redistribution and reproduction in particular requires that the authors and source are credited.

The license is subject to the Beilstein Journal of Nanotechnology terms and conditions: (https://www.beilstein-journals.org/bjnano)

The definitive version of this article is the electronic one which can be found at:

doi:10.3762/bjnano.10.2 